\title{
Intraseasonal Variability of Cross-Slope Flow in the Northern South China Sea
}

\author{
QIANG WANG \\ State Key Laboratory of Tropical Oceanography, South China Sea Institute of Oceanology, Chinese Academy of Sciences, \\ and Southern Marine Science and Engineering Guangdong Laboratory (Guangzhou), Guangzhou, China \\ Weidong Zhou, Lili Zeng, Ju Chen, And YunKai He \\ State Key Laboratory of Tropical Oceanography, South China Sea Institute of Oceanology, Chinese Academy of Sciences, \\ Guangzhou, China \\ DONGXIAO WANG \\ School of Marine Sciences, Sun Yat-Sen University, Guangzhou, China
}

(Manuscript received 25 November 2019, in final form 20 May 2020)

\begin{abstract}
Cross-slope flow plays an important role in the exchange of material, heat, and momentum between the continental shelf and the open sea. In the northern South China Sea (SCS), long-period observations confirm that there is significant cross-slope flow. The variability of this flow is dominated by the intraseasonal component (i.e., the 10-90-day period band) that contributes $74.6 \%$ of the total standard deviation. The $10-90$-day bandpassed cross-slope flow exhibits almost the same direction vertically in the observed layers, and its first empirical orthogonal function, whose direction is also not changed, contributes $86.7 \%$ to its total variance. The strong $10-$ 90-day bandpassed cross-slope flow is phase locked to the boreal winter half year. The intraseasonal variability of cross-slope flow is mainly associated with mesoscale eddies west to the Luzon Strait. The contrasting baroclinic instability growth rates, strong in winter and weak in summer, result in a seasonal cycle of mesoscale eddy kinetic energy, that is, vigorous in winter and weak in summer, which explains the winter phase lock. The interannual variability of baroclinic instability growth rate is mainly determined by the vertical shear of velocity. The strongest vertical shear of velocity from 2014 to 2016 occurred in the winter of 2016/17 and induced the most rapid baroclinic instability growth rate and consequently the largest mesoscale eddy kinetic energy, which resulted in the strongest intraseasonal variability of cross-slope flow. The vertical shear of velocity in the northern SCS is mainly determined by the Luzon Strait transport.
\end{abstract}

\section{Introduction}

The South China Sea (SCS) is the largest marginal sea in the western Pacific Ocean. Its large-scale circulation exhibits seasonal shifts under monsoon forcing and strait water exchange (Wyrtki 1961; Hu et al. 2000; Yuan 2002, 2006; Gan et al. 2006, 2016; Tian et al. 2006; Yang et al. 2019). In winter, there is a basin-scale cyclonic circulation that is due to the northeasterly winter monsoon (Wang et al. 2008; Wang et al. 2013a; Chen and Xue 2014; Qiu et al. 2015, 2019a). The winter west boundary current of SCS also varies under climate change (Fang et al. 2013; Zhao and Zhu 2016). The circulation reverses during the southwesterly summer monsoon, which

Corresponding author: Dr. Dongxiao Wang, dxwang@scsio.ac.cn drives a cyclonic (anticyclonic) gyre in the northern (southern) SCS, inducing an eastward jet between the gyres (Xie et al. 2003; Wang et al. 2006; G. Wang et al. 2010; Gan and Qu 2008).

In the northern SCS, there also are distinct seasonal circulation patterns (Hu et al. 2000; Cheng et al. 2015). In winter, there are three adjacent bandlike currents with alternating directions: the Guangdong Coastal Current, the SCS Warm Current, and the northern branch of the SCS western boundary current (Guo et al. 1985; Hu et al. 2000; D. Wang et al. 2010; Wang et al. 2011). In summer, the water mainly flows northeastward (Gan et al. 2006).

Along the slope of the northern SCS, there is a perpetual southwestward slope flow in the upper layer (Fig. 1), which enhances in winter and weakens in summer (Hu et al. 2000; Shu et al. 2018). Forced Rossby 


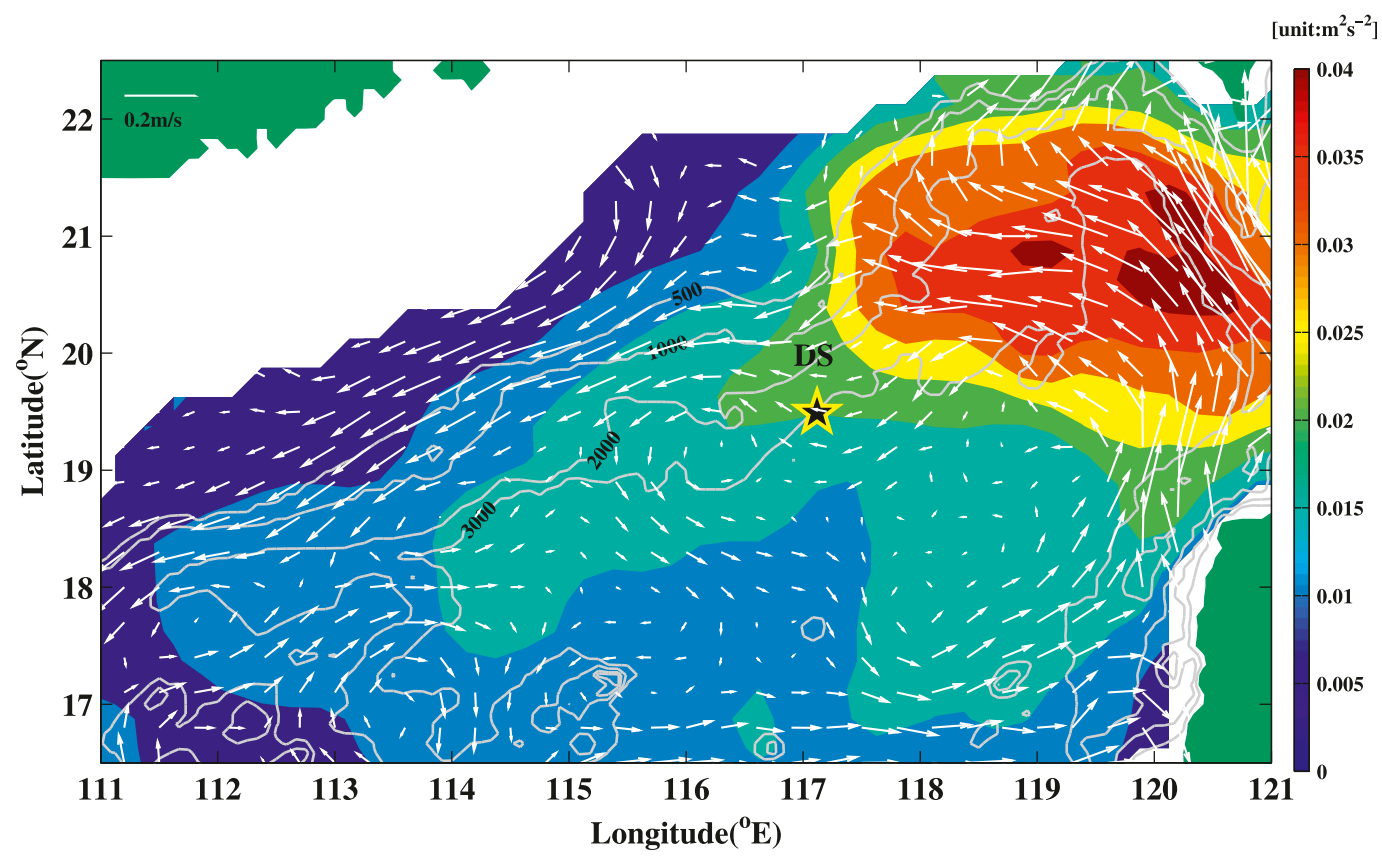

FIG. 1. Distribution of intraseasonal sea surface kinetic energy derived from AVISO geostrophic velocity. The gray lines indicate the topography. The black star indicates the mooring station. The intraseasonal sea surface kinetic energy is defined as the STD of the kinetic energy of the 10-90-day bandpassed geostrophic velocity. The vectors are the climatological distribution of AVISO geostrophic velocity.

wave, originating to the northwest of Luzon Island and propagating northwestward, crosses the slope and induces the slope flow swing (Yang and Liu 2003; Chow et al. 2008). Because of the variation of Kuroshio intrusion and monsoon, the slope flow also exhibits significant interannual variability (Zhu et al. 2015; Zhao and Zhu 2016; Zu et al. 2019; Wang et al. 2020a). The slope flow direction reverses in the middepth around $500-1000 \mathrm{~m}$ and forms an offshore jet around $117^{\circ} \mathrm{E}$ on the northern SCS slope as a result of the joint effect of baroclinicity and relief (JEBAR; Wang et al. 2013b), which contributes to the variation of sedimentary systems (Chen et al. 2013; Li et al. 2016; Chen et al. 2017; X. Wang et al. 2018). West to the Luzon Strait, it is the Kuroshio loop that modulates the baroclinic instability, and then the mesoscale eddy activates in the northern SCS (Zhang et al. 2017; Yang et al. 2019; Wang et al. 2020b).

In addition to the bandlike currents in the northern SCS, there is a significant cross-slope flow component (Wang et al. 2013b; Wang et al. 2015b). The warm saline Kuroshio water encounters cool fresh SCS water in the northern SCS, generating a strong density gradient along the slope, which induces a strong JEBAR (Wang et al. 2013b). To balance the negative JEBAR, the water column tends to move downslope. On a climatological scale, the JEBAR is the main driver of the cross-slope flow, and wind stress curl is secondary (Wang et al. 2015b).
Mesoscale eddies are another important factor driving the cross-slope flow on an intraseasonal scale (Q. Wang et al. 2018). When an eddy propagates past a fixed location, net cross-slope transport can be induced by asymmetry in the horizontal and vertical structure of the eddy and by its evolution. The cross-slope flow also exerts great effect on the bottom flow variability, transferring the upper-layer flow variability toward the bottom via the first baroclinic mode (Wang et al. 2019).

In the SCS, mesoscale eddies are an important component of dynamical oceanography across the range of scales (Wang et al. 2003; Xiu et al. 2010; Feng et al. 2017; Sun et al. 2018; Qiu et al. 2019b; Lian et al. 2019; Chu et al. 2020; $\mathrm{Zu}$ et al. 2019). Mesoscale eddies exert great impact on the thermohaline structures in the northern SCS, which can induce maximum temperature anomalies from $-2.5^{\circ}$ to $2.2^{\circ} \mathrm{C}$ (Zhao et al. 2017). The mesoscale eddy-induced transports are an important process of the interior dynamics of SCS circulation, which feed back to the adjustment of large-scale circulation (Zhuang et al. 2010a,b; Nan et al. 2011; Chen et al. 2012; Wang et al. 2015a; Zhang et al. 2016; Zhao et al. 2017; Sun et al. 2017, 2019) and induce active air-sea interaction (Sun et al. 2016, 2020). The generation of mesoscale eddies is mainly attributed to the Kuroshio shedding (Li et al. 1998; Li et al. 2002; Jia and Liu 2004, 2005; Yuan et al. 2007; Zhang et al. 2015, 2017; Xia et al. 2016), orographic wind jets (Wang et al. 2008), 
TABLE 1. Moorings, instruments, and deployment periods (ADCP: acoustic Doppler current profilers).

\begin{tabular}{ccccccc}
\hline \hline $\begin{array}{c}\text { Station } \\
\text { name }\end{array}$ & $\begin{array}{c}\text { Water } \\
\text { depth }(\mathrm{m})\end{array}$ & $\begin{array}{c}\text { Location } \\
(\text { lat, lon })\end{array}$ & $\begin{array}{c}\text { Measurement } \\
\text { period }\end{array}$ & $\begin{array}{c}\text { Instrument } \\
\text { type }\end{array}$ & $\begin{array}{c}\text { Measurement } \\
\text { range (m) }\end{array}$ & $\begin{array}{c}\text { Sampling } \\
\text { interval }\end{array}$ \\
\hline DS & 3092 & $\left(19.49^{\circ} \mathrm{N}, 117.12^{\circ} \mathrm{E}\right)$ & $\begin{array}{l}\text { 20 Sep 2014-10 Aug 2018 } \\
\text { 20 Sep 2014-15 Jul 2017 }\end{array}$ & $\begin{array}{c}\text { Upward 75K ADCP } \\
\text { Upward 75K ADCP }\end{array}$ & $\begin{array}{c}<402 \\
506-898\end{array}$ \\
\hline
\end{tabular}

and baroclinic instability (Zhuang et al. 2010a; Chen et al. 2012; Zu et al. 2013; Wang et al. 2020b).

Cross-slope flow is the key ocean process that drives the exchange of material between the continental shelf and open sea. However, our understanding of this process is still limited due to the scarcity of long-term continuous observations. Fortunately, we have more than four years of mooring observations on the northern SCS slope, in an area with active mesoscale eddies (Fig. 1). Thus, the structure and variability of the cross-slope flow in the northern SCS are investigated in this study.

The remainder of this paper is organized as follows: Section 2 describes the data and method. Section 3 gives results for the intraseasonal variability of cross-slope flow. The possible mechanism that controls the vertical shear of velocity in the northeast SCS is discussed in section 4. The discussion and conclusions are given in sections 5 and 6 , respectively.

\section{Data and method}

\section{a. Data}

Data were obtained from mooring station on the northern SCS continental slope covering the period from 20 September 2014 to 10 August 2018 (station DS) (Fig. 1). The sampling time interval was $1 \mathrm{~h}$, and the vertical spatial resolution was $8 \mathrm{~m}$. More details are listed in Table 1 . Any velocity that is larger than 3 times the standard
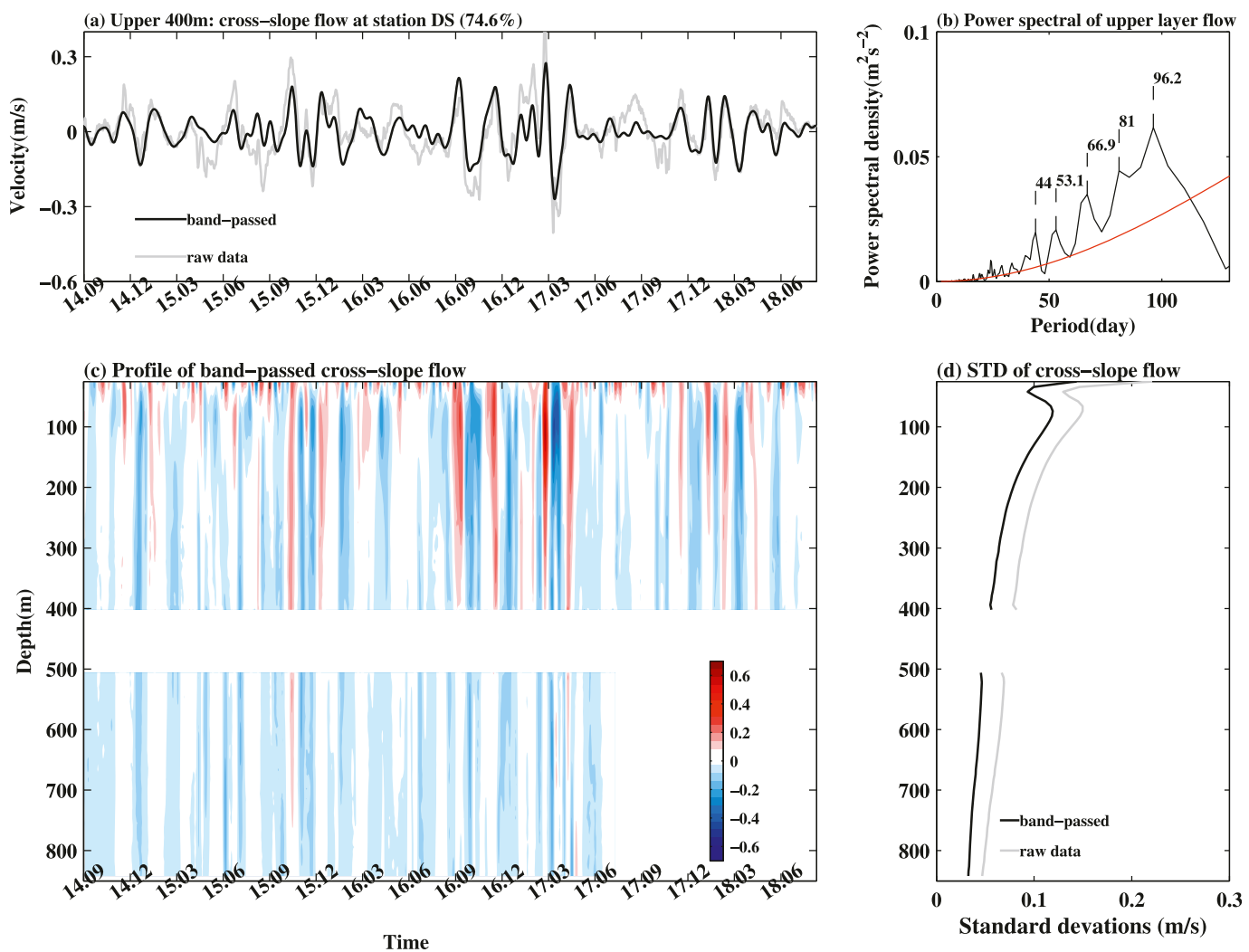

FIG. 2. (a) Time series of cross-slope flow averaged over the upper $400 \mathrm{~m}$ at station DS. The gray line indicates the raw data, and the black line indicates the 10-90-day bandpassed cross-slope flow. (b) Power spectra of the raw crossslope flow averaged over the upper $400 \mathrm{~m}$; the red line represents the $95 \%$ significance level based on a Student's $t$ test. (c) Time series of 10-90-day bandpassed cross-slope flow profile, where red indicates onshore and blue indicates offshore. (d) Profiles of STD associated with raw (gray line) and 10-90-day bandpassed (black line) cross-slope flow. In (d), the STD is calculated on the basis of the period for which both the upper- and lower-layers' data are available. 

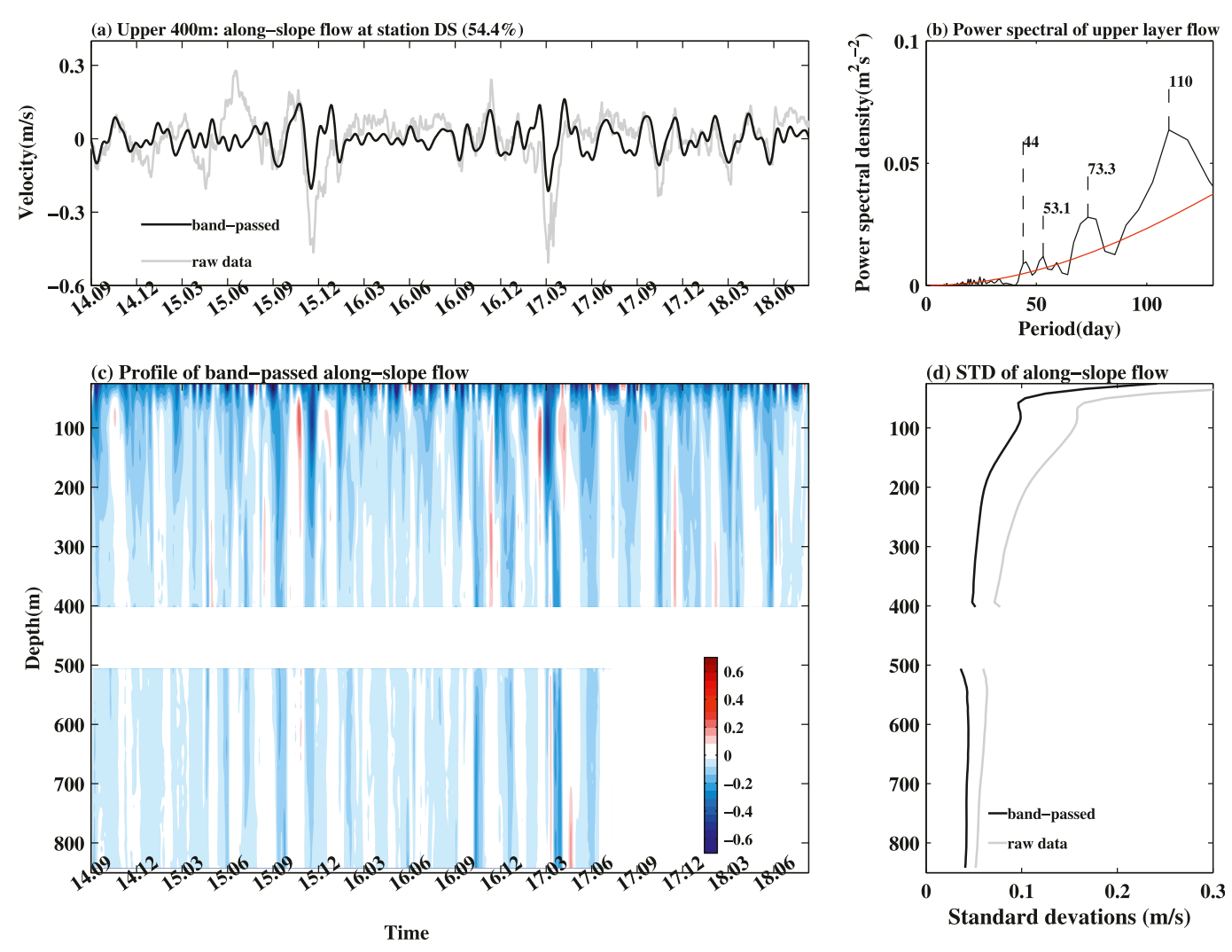

FIG. 3. As in Fig. 2, but for along-slope flow.

deviation (STD) at that depth was defined as an invalid value. Short gaps caused by invalid data were subsequently filled by linear interpolation. In this study, a 24-h low-pass filter was applied to all the data to remove tides and inertial oscillations, and then the data were averaged over $24 \mathrm{~h}$ (hereinafter, raw data). In this paper, we define the 1090-day bandpassed velocity as the intraseasonal variability.

Surface geostrophic flow is provided by the French Archiving, Validation and Interpretation of Satellite Oceanographic Data (AVISO) project. AVISO supplies $1 / 4^{\circ}$ horizontal resolution daily velocity from 1993 to the present. Based on the comparison of mesoscale eddy detection algorithms (Lian et al. 2019), we selected the eddy detection scheme based on the geometry of the velocity vectors (Nencioli et al. 2010; Dong et al. 2012, 2014). This method has been applied in studies of mesoscale-eddy-induced cross-slope flow (Q. Wang et al. 2018; Wang et al. 2019). The mesoscale eddy kinetic energy is defined as the total sea surface kinetic energy within the mesoscale eddy boundaries.

Temperature data are taken from the quality-controlled Met Office Hadley Centre subsurface temperature and salinity objective analyses, EN4 (version 4.2.0; Good et al. 2013). We use the EN4 temperature data at $1^{\circ} \times 1^{\circ}$ spatial resolution over the period 1950-2016. This dataset has been utilized to investigate the interannual variability of the thermal state of the SCS (Zeng et al. 2016).

Results from the OGCM for the Earth Simulator (OFES; Sasaki et al. 2007) are utilized in this study. OFES was run at $0.1^{\circ} \times 0.1^{\circ}$ spatial resolution and 54 vertical levels, forced by National Centers for Environmental Prediction-National Center for Atmospheric Research reanalysis data. The monthly ocean velocity and wind stress over the period 1950-2016 used in this study are supplied by OFES. From the OFES outputs, the Luzon Strait transport (LST) is calculated, which is the integration of the zonal velocity in the upper $250 \mathrm{~m}$ along $121^{\circ} \mathrm{E}$ in the Luzon Strait.

\section{b. Baroclinic instability}

The baroclinic instability is estimated using a linear $2^{1 / 2}$-layer model with a zonal mean flow $U_{i}$. Following Qiu (1999), the baroclinic instability growth rate can be acquired from a quadratic polynomial for the complex phase speed $c=c_{r}+c_{i}$ :

$$
\begin{aligned}
& c^{2}-\left(U_{1}+U_{2}-\frac{P+Q}{R}\right) c \\
& +\left(U_{1} U_{2}+\frac{\Pi_{1 y} \Pi_{2 y}-U_{1} P-U_{2} Q}{R}\right)=0,
\end{aligned}
$$


(a) EOF of cross-slope flow

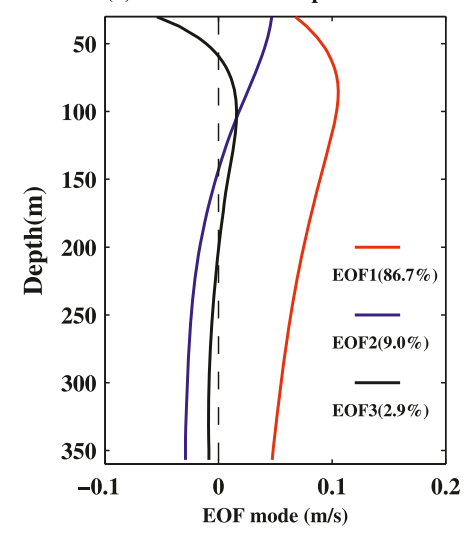

(c) PC: cross-slope flow

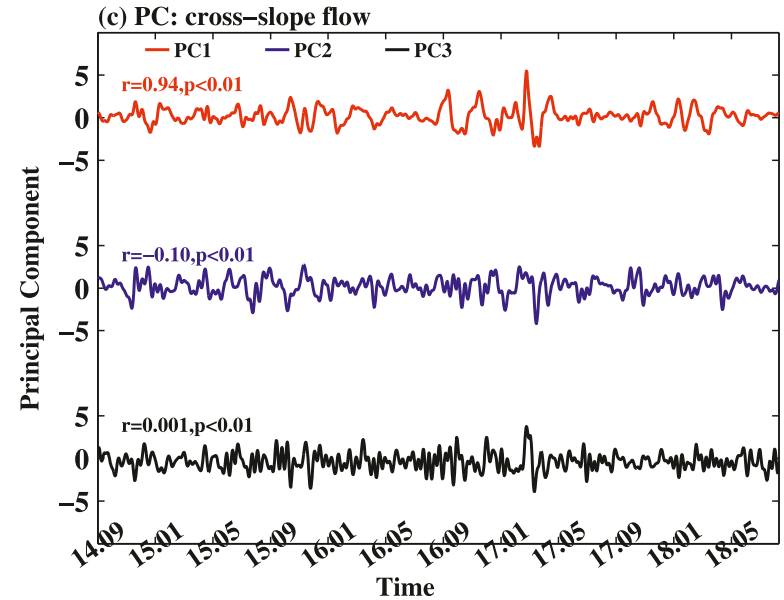

(b) EOF of along-slope flow

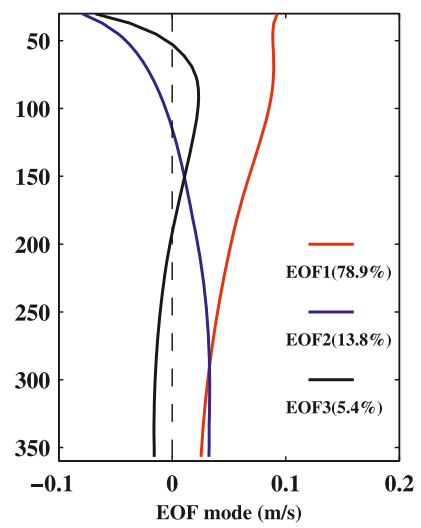

(d) PC: along-slope flow

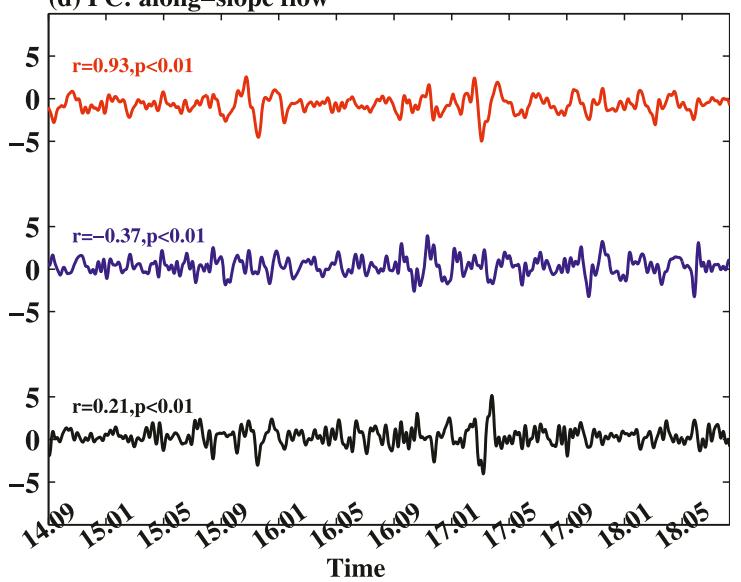

FIG. 4. The first three EOF mode patterns of 10-90-day bandpassed (a) cross-slope and (b) along-slope flow. Also shown are the first three PCs of 10-90-day bandpassed (c) cross-slope and (d) along-slope flow.

where

$$
\begin{aligned}
\Pi_{1 y} & =\beta+\frac{1}{\gamma \delta \lambda^{2}}\left(U_{1}-U_{2}\right), \\
\Pi_{2 y} & =\beta-\frac{1}{\gamma \lambda^{2}}\left(U_{1}-U_{2}-\gamma U_{2}\right), \\
P & =\left(K^{2}+\frac{1}{\gamma \delta \lambda^{2}}\right) \Pi_{2 y}, \\
Q & =\left(K^{2}+\frac{1+\gamma}{\gamma \lambda^{2}}\right) \Pi_{1 y}, \\
R & =\frac{P Q}{\Pi_{1 y} \Pi_{2 y}}-\frac{1}{\gamma^{2} \delta \lambda^{4}}, \\
\delta & \equiv H_{1} / H_{2}, \\
\gamma & \equiv \frac{\rho_{2}-\rho_{1}}{\rho_{3}-\rho_{2}}, \quad \text { and }
\end{aligned}
$$

$$
\lambda \equiv \frac{1}{f_{o}} \sqrt{\frac{\rho_{3}-\rho_{2}}{\rho_{o}} g H_{2}}
$$

Here $f_{o}$ is the Coriolis parameter at reference latitude, $\beta$ is the meridional gradient of the Coriolis parameter, $\rho_{n}$ $(n=1,2,3)$ is the density at layer $n, \rho_{o}$ is the reference density, $\gamma$ is the stratification ratio, $H_{n}(n=1,2)$ is the mean thickness of layer $n, g$ is the acceleration due to gravity, and $K^{2}=k^{2}+l^{2}$ is the total wavenumber. When the meridional wavenumber $l$ is fixed, the baroclinic instability growth rate (i.e., $k c_{i}$ ) can be calculated as a function of zonal wavenumber $k$.

\section{Intraseasonal variability of cross-slope flow}

a. Characteristics of the intraseasonal variability of cross-slope flow in the northern South China Sea

To identify the contribution of the intraseasonal variability to the total cross-slope velocity field, 10-90-day 

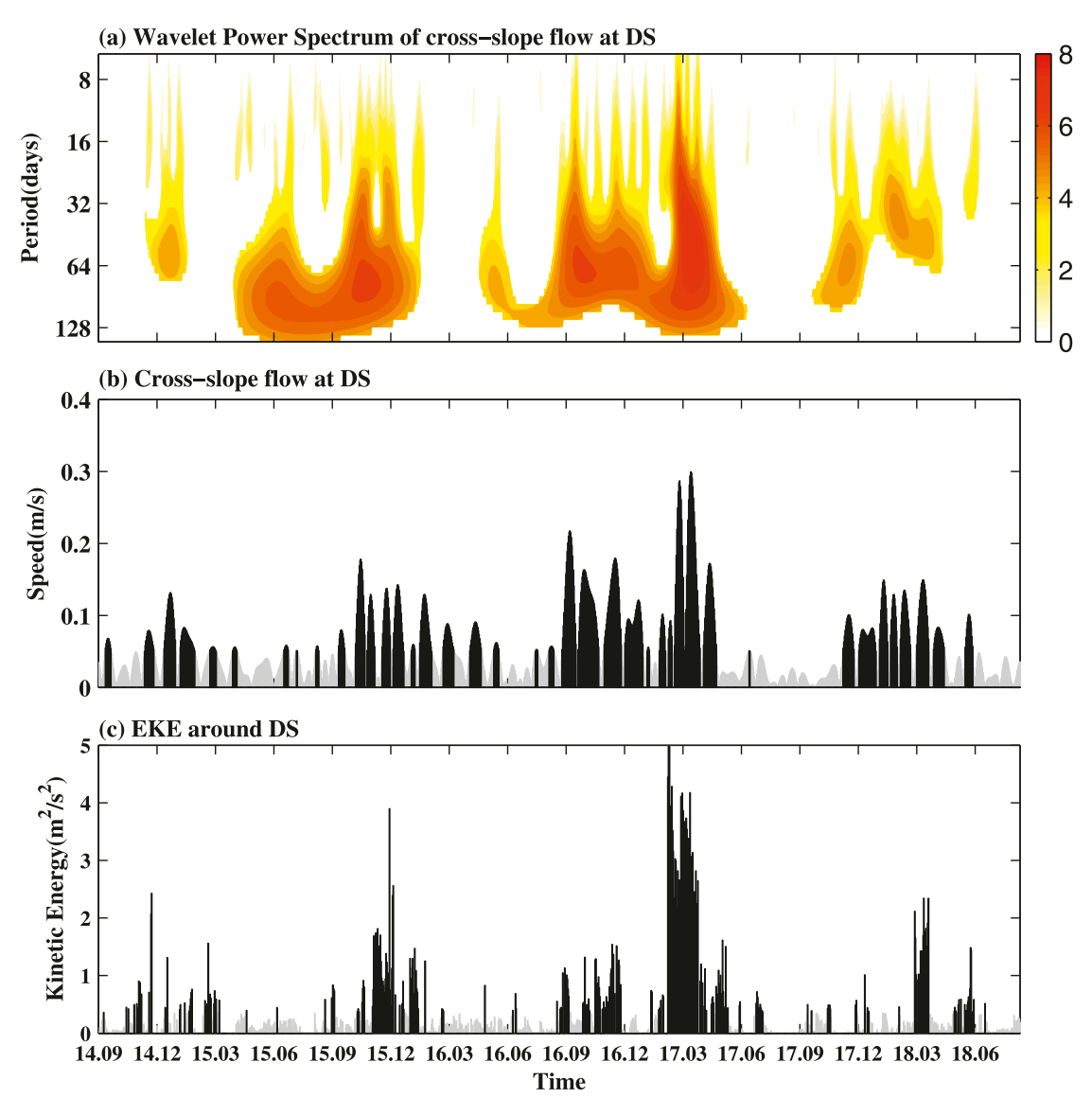

FIG. 5. (a) Wavelet power spectrum of raw cross-slope flow averaged over the upper $400 \mathrm{~m}$ at station DS; values that pass a 95\% significance level test against red noise are shown. (b) Time series of 10-90-day bandpassed cross-slope speed averaged over the upper $400 \mathrm{~m}$ at station DS. (c) As in (b), but for surface mesoscale eddy kinetic energy (EKE) derived from the AVISO dataset. In (b) and (c), velocities with amplitude larger than their STD are shown in black.

bandpassed and raw data are shown in Fig. 2a. The amplitude and phase of the bandpassed cross-slope velocity generally follow those of the raw data. The ratio of the STDs of the bandpassed and raw data [i.e., (STD of 10-90-day bandpassed)/(STD of raw data)] is $74.6 \%$, demonstrating that the intraseasonal variability is the dominant period range of the cross-slope flow in the northern SCS. A spectral analysis was also applied to the raw cross-slope velocity (Fig. 2b). The dominant period ranges from 44 to 96.2 days, falling within the intraseasonal variability band. The 10-90-day bandpassed cross-slope flow exhibits the same direction vertically in the observed layers, with upper-layer intensification (Figs. 2c,d). The alternating positive and negative cross-slope velocities are associated with mesoscale eddies (Q. Wang et al. 2018).

For the along-slope velocity, the contribution of the intraseasonal variability to the raw data field reduces to $54.4 \%$ (Fig. 3a). The peaks of short periods such as 44 and 53.1 days are weak, and the dominant period range extends to 110 days (Fig. 3b). This indicates a long-period shift of the along-slope velocity relative to the cross-slope flow. The direction of 10-90-day bandpassed along-slope flow is almost not changed vertically in the observed layers, featuring a dominant westward direction (Fig. 3c). The westward flow is the northern SCS slope flow; that is, the northern branch of the SCS western boundary flow (Shu et al. 2018; Wang et al. 2020a). The amplitude of the along-slope flow still exhibits upper-layer intensification (Fig. 3d).

To investigate the vertical structure of the velocity profiles, an empirical orthogonal function (EOF) analysis is applied to the 10-90-day bandpassed cross-slope and along-slope velocities (Fig. 4). The first EOF modes of both the cross-slope and along-slope velocity contribute more than $70.0 \%$ to the total variance, which confirms that the same flow direction mode dominates the vertical structure in the upper $400 \mathrm{~m}$ (Figs. 4a,b). The first EOF mode contribution to the cross-slope velocity is as high as $86.7 \%$ and is strongly correlated with the 
(a) Cold eddy path:Impact DS station

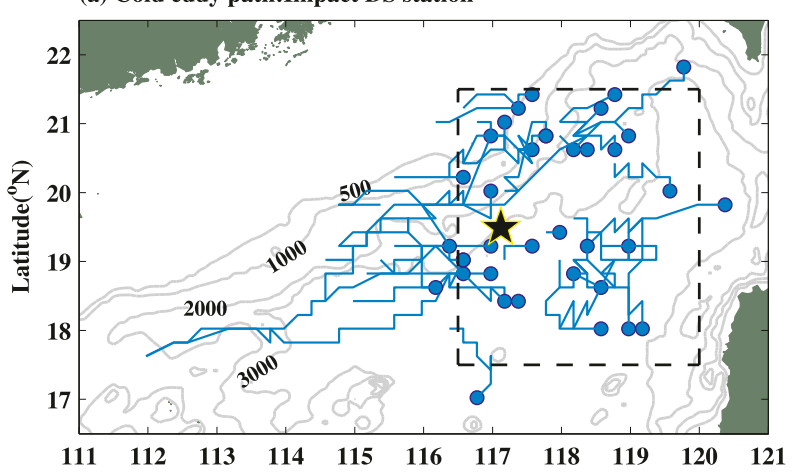

(b) Warm eddy path:Impact DS station

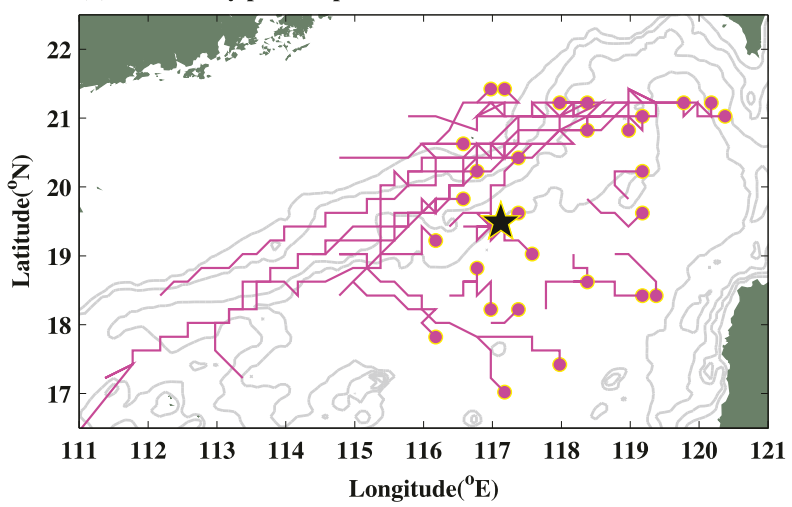

FIG. 6. Paths of (a) cold and (b) warm mesoscale eddies from AVISO data. The gray lines are topography. The black star is mooring station DS. Blue or red dots are generation locations of mesoscale eddies. The dashed black box in (a) indicates the area used to diagnose the mesoscale EKE (Fig. 7) and baroclinic instability (Fig. 8).

vertically averaged intraseasonal cross-slope velocity with a correlation of 0.94 (Fig. 4c). The second and third principal components (PCs) are not correlated with the vertically averaged intraseasonal cross-slope velocity. For the along-slope velocity, the second EOF mode is also significant, with a contribution of $13.8 \%$ to the total variance (Fig. 4b), and the first and second PCs are both related to the vertically averaged intraseasonal alongslope velocity (Fig. 4d).

\section{b. Cross-slope flow intraseasonal variability and mesoscale eddies}

A wavelet power spectrum analysis (Grinsted et al. 2004) has been applied to the raw cross-slope velocity vertically averaged over the upper $400 \mathrm{~m}$ (Fig. 5a). The large amplitude of the 10-90-day bandpassed crossslope velocity is consistent with the occurrence of strong 10-90-day period energy (Figs. 5a,b). The burst of intraseasonal variability of the cross-slope velocity mainly occurs in the boreal winter half year and has significant interannual variability, being strongest in the winter of 2016/17 and weakest in the winter of 2014/15 (Fig. 5b). To identify the source of the cross-slope velocity intraseasonal variability, the sea surface mesoscale eddy kinetic energy at station DS is investigated (Fig. 5c). The resemblance between them demonstrates that the cross-slope flow is related to the mesoscale eddies in the northern SCS. When the mesoscale eddy is active, the cross-slope flow will be enhanced on the intraseasonal scale. Thus, the intraseasonal variability of cross-slope flow behaves difference among years due to the interannual variability of mesoscale eddy activities.

The intraseasonal variability of cross-slope flow is closely related to the mesoscale eddies, and each mesoscale eddy that can affect the station DS has been tracked during the observation period (Fig. 6). Both warm and cold eddies are mainly generated west to the Luzon Strait and then generally propagate westward (Figs. 6a,b).

The seasonal cycle of the mesoscale eddies kinetic energy within the area indicated by the black box in Fig. 6a shows the winter-half-year intensification (Fig. 7), which explains why the burst of 10-90-day bandpassed crossslope flow mainly occurs in the winter half years (Fig. 5b).

\section{Dynamics of cross-slope flow intraseasonal variability}

Baroclinic instability is an important mechanism that transforms mean potential energy to eddy potential

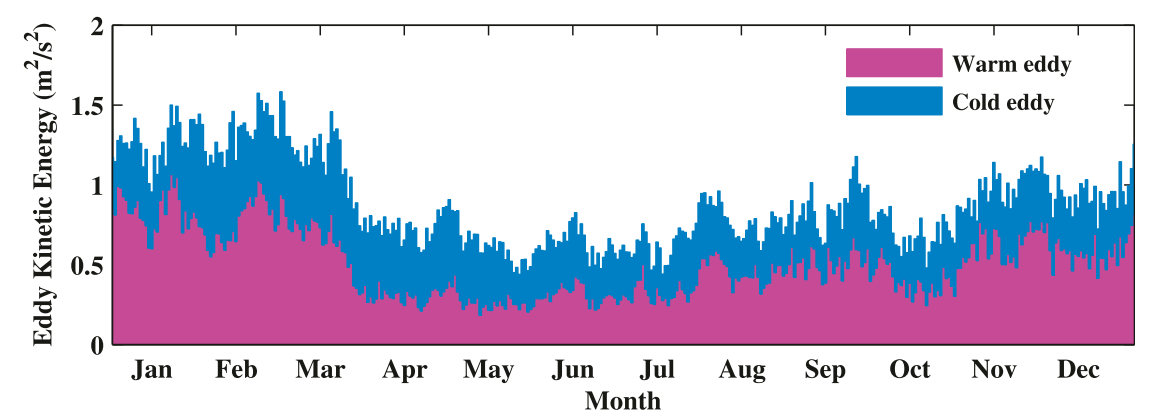

FIG. 7. Seasonal cycle of total sea surface mesoscale EKE within the black box marked in Fig. 6a. 

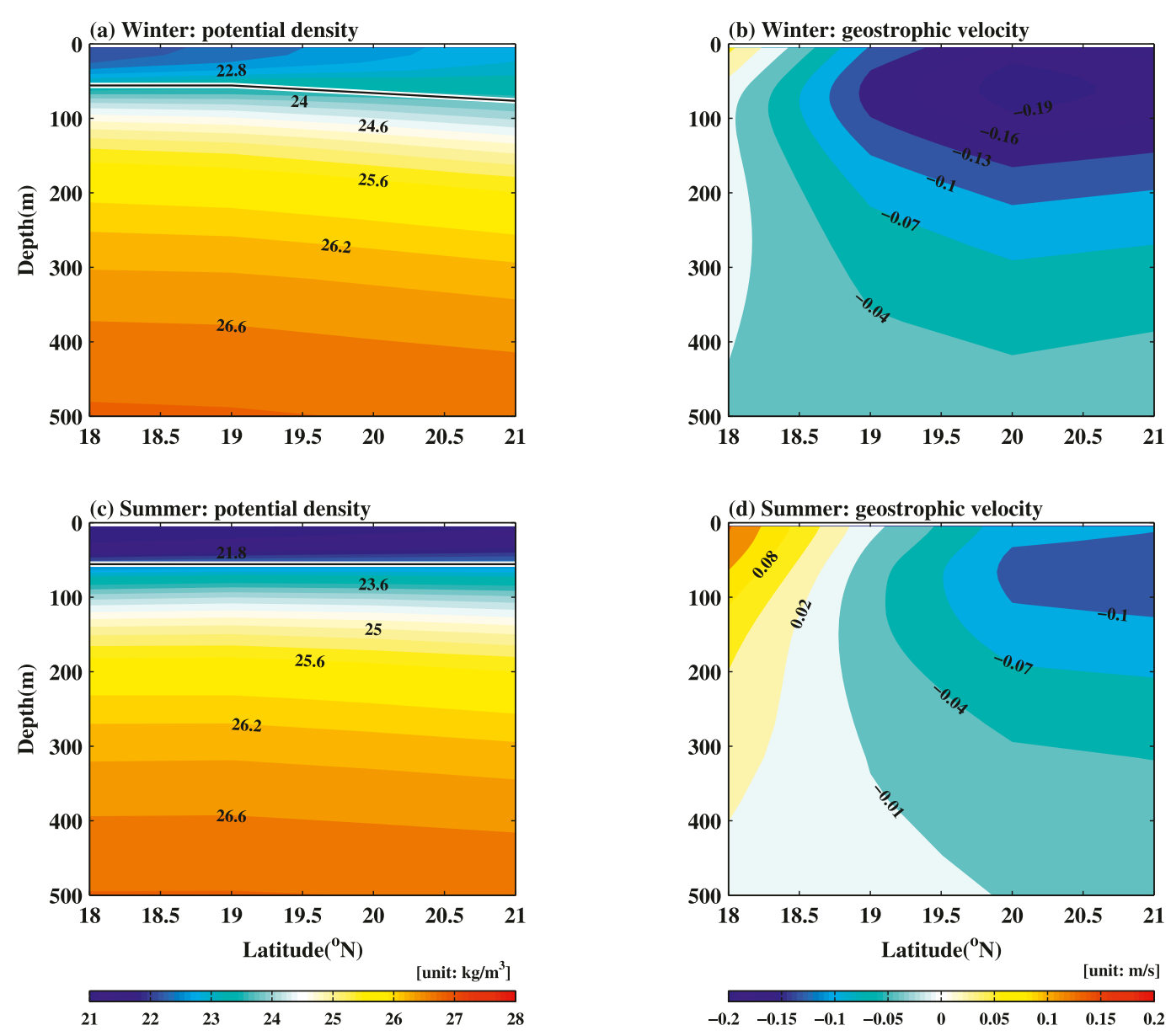

FIG. 8. (left) Meridional density structure and (right) zonal geostrophic velocities along $119^{\circ} \mathrm{E}$ in (a),(b) winter and (c),(d) summer, within the area indicated by the black box in Fig. 6a. The data are from EN4, and the reference level used to calculate the geostrophic flow is $1500 \mathrm{~m}$.

energy and then forms mesoscale eddies (Qiu 1999). Most of the mesoscale eddies that affect the station DS are generated west to the Luzon Strait (Fig. 6), so we show in Fig. 8 the potential density and zonal geostrophic velocity profiles along $119^{\circ} \mathrm{E}$ in boreal winter and summer. In winter, the stratification ratio of potential density is small due to a large loss of heat at the sea surface and strong mixing (Fig. 8a). A strong westward zonal geostrophic flow occurs in winter, which intensifies in the upper layer and results in a strong vertical shear of zonal flow (Fig. 8b). In contrast, in summer the upper-layer density lightens, producing a

TABLE 2. Parameter values for the calculation of instability growth rate.

\begin{tabular}{|c|c|c|c|c|}
\hline Parameter & Climatological winter & Winter of 2014 & Winter of 2015 & Winter of 2016 \\
\hline$f_{o}\left(\mathrm{~s}^{-1}\right)$ & $4.98 \times 10^{-5}$ & - & - & - \\
\hline$\beta\left(\mathrm{m}^{-1} \mathrm{~s}^{-1}\right)$ & $2.16 \times 10^{-11}$ & - & - & - \\
\hline$H_{1}(\mathrm{~m})$ & 100 & - & - & - \\
\hline$H_{2}(\mathrm{~m})$ & 150 & - & - & - \\
\hline$U_{1}\left(\mathrm{~m} \mathrm{~s}^{-1}\right)$ & -0.16 & -0.20 & -0.22 & -0.21 \\
\hline$U_{2}\left(\mathrm{~m} \mathrm{~s}^{-1}\right)$ & -0.09 & -0.11 & -0.12 & -0.10 \\
\hline$\rho_{1}\left(\mathrm{~kg} \mathrm{~m}^{-3}\right)$ & 23.49 & 23.58 & 23.56 & 23.55 \\
\hline$\rho_{2}\left(\mathrm{~kg} \mathrm{~m}^{-3}\right)$ & 25.17 & 25.25 & 25.21 & 25.33 \\
\hline$\rho_{3}\left(\mathrm{kgm}^{-3}\right)$ & 27.13 & 27.12 & 27.11 & 27.18 \\
\hline$\gamma$ & 0.857 & 0.893 & 0.868 & 0.962 \\
\hline$l\left(\mathrm{~m}^{-1}\right)$ & $1.0 \times 10^{-5}$ & - & - & - \\
\hline
\end{tabular}


(a) Real calculation $(k c r)$

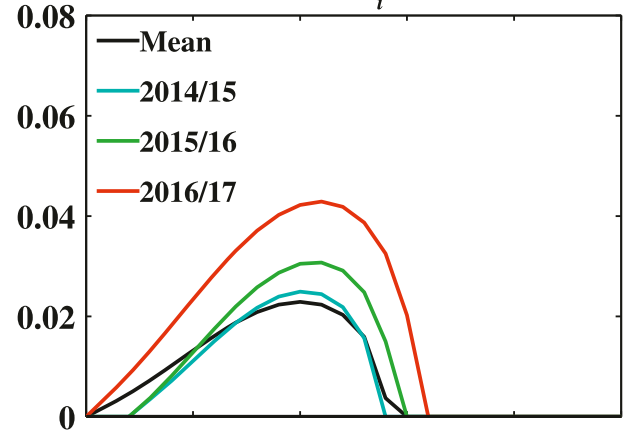

(b) Fixed stratification $\left(k c_{i} \rho\right)$

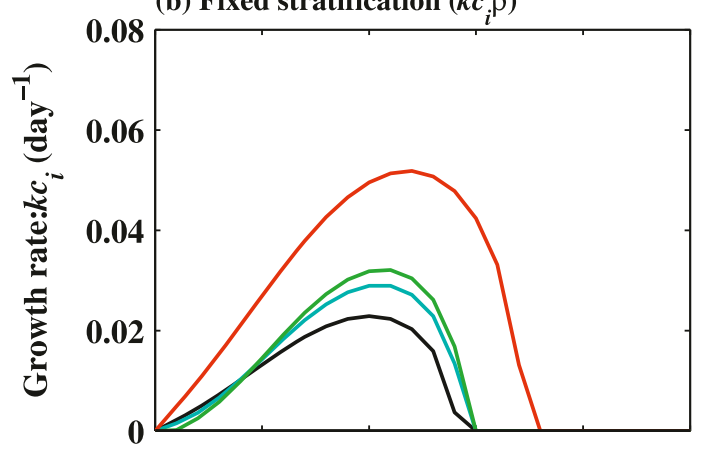

(c) Fixed velocity vertical shear $(k c u)$

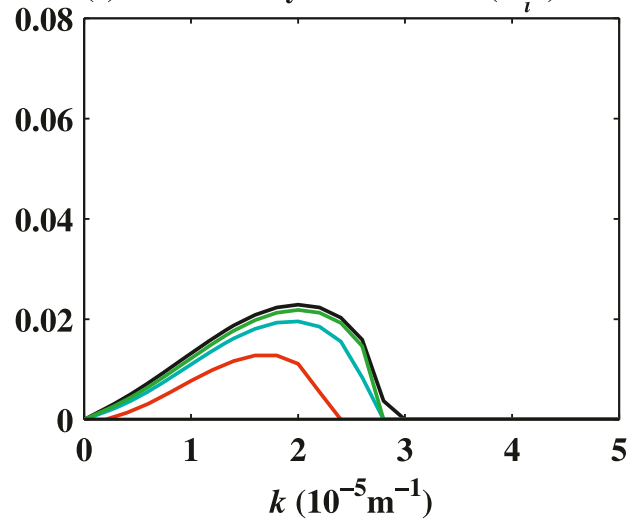

(d) $k c_{i} \rho$ and $k c r$

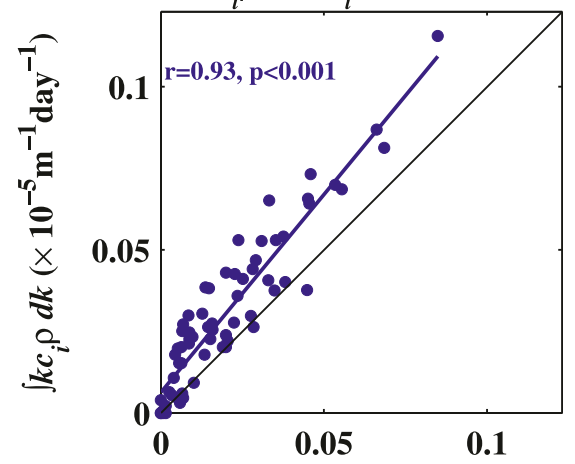

(e) $k c u$ and $k c r$

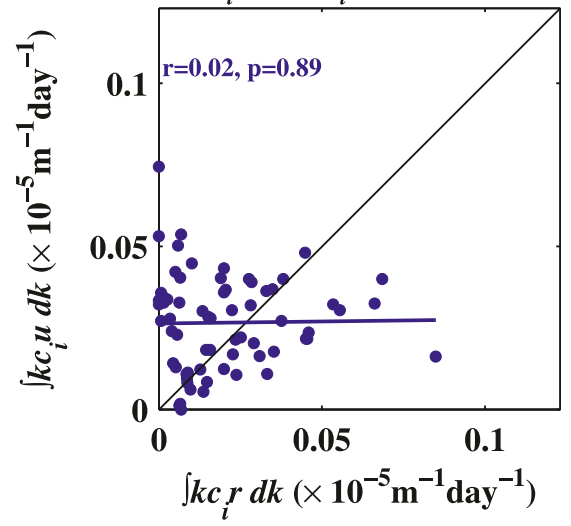

FIG. 9. (a) Growth rate $k c_{i} r$ as a function of zonal wavenumber $k$, calculated from Eq. (1). (b) As in (a), but with the stratification set to the climatological value $k c_{i} \rho$. (c) As in (a), but with the vertical shear of velocity set to the climatological value $k c_{i} u$. (d) Relationship between integrated $k c_{i} \rho$ and $k c_{i} r$ from 1950 to 2016. (e) As in (d), but between $k c_{i} u$ and $k c_{i} r$. Here $k c_{i} r$ is the winter growth rate of real parameters, $k c_{i} \rho$ is the winter growth rate with the climatological stratification, and $k c_{i} u$ is the winter growth rate with the climatological vertical shear of zonal velocity.

larger stratification ratio due to the intense heating by shortwave radiation (Fig. 8c). The zonal geostrophic flow also weakens, with a small vertical shear of zonal flow (Fig. 8d).

Chen et al. (2012) attributed the seasonal variability of the mesoscale eddy generation west of the Luzon Strait to the seasonal cycle of baroclinic instability induced by weak (strong) stratification and strong (weak) zonal vertical shear in winter (summer). To investigate the seasonal and interannual variability of the mesoscale eddy kinetic energy west to Luzon Strait, we consider the vertically sheared system of these zonal currents in a 21/2-layer reduced-gravity model [i.e., Eq. (1)].

In Table 2, we list the parameter values used in the baroclinic instability calculation, which are estimated from the EN4 dataset along $119^{\circ} \mathrm{E}$. The winter pycnocline 
(a) Stratification ratio
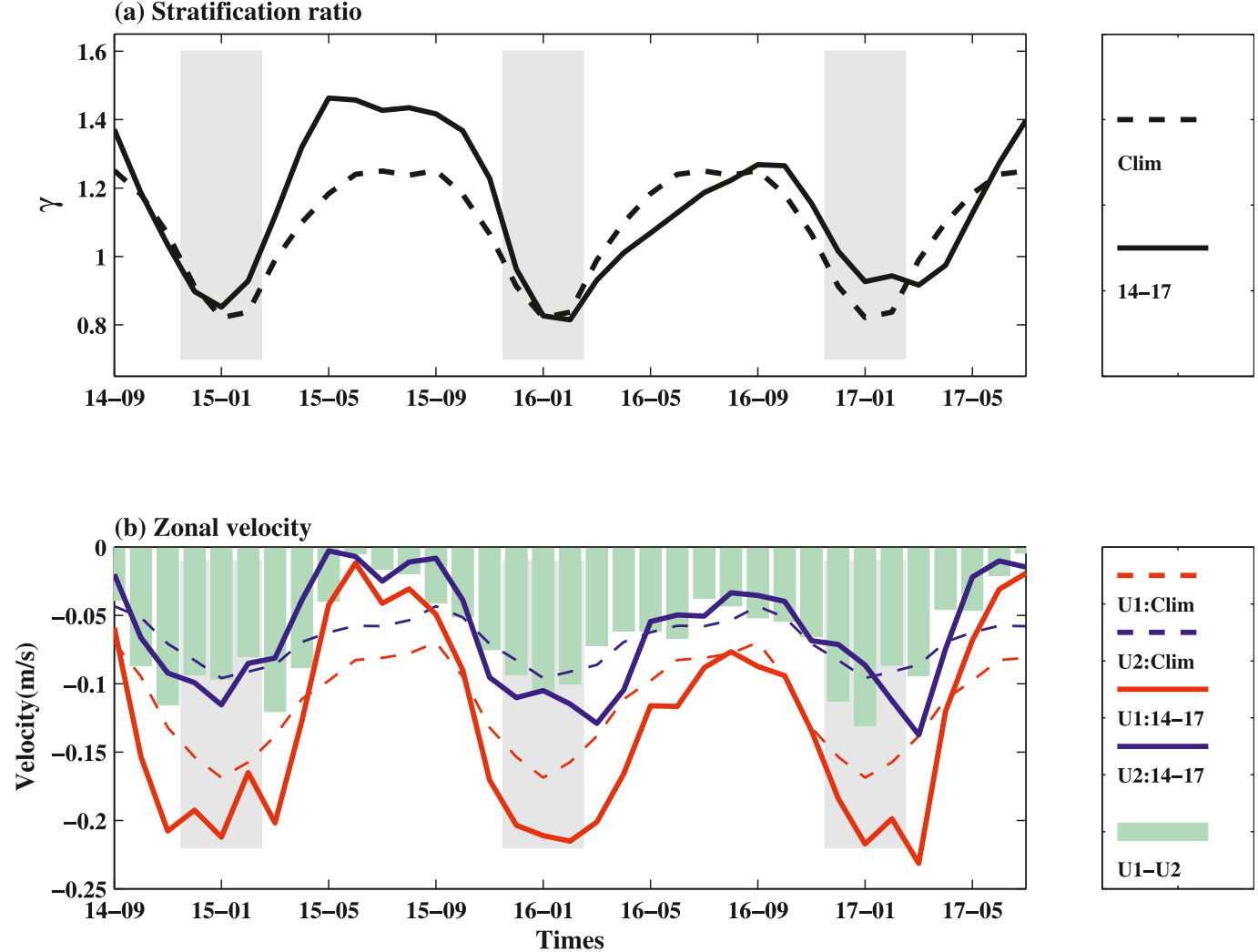

FIG. 10. Time series of (a) stratification ratio and (b) upper-layer $\left(U_{1}\right)$ and lower-layer $\left(U_{2}\right)$ zonal velocities averaged within the black box marked in Fig. 6a. In (b), the green bars indicate the difference between $U_{1}$ and $U_{2}$ from 2014 to 2017. The gray bars indicate the period of winter.

in the northern SCS is about $80 \mathrm{~m}$, and $H_{1}$ and $H_{2}$ were set as 100 and $150 \mathrm{~m}$, respectively.

In summer, there is strong stratification ratio and weak vertical shear of zonal flow (Figs. 8c,d), and the background field marginally satisfies baroclinic instability, which explains why there are weak mesoscale eddies activities at this time. In winter, the climatological most unstable wave has a growth rate $k c_{i} \approx 0.02$ day $^{-1}$ (Fig. 9a), which is consistent with the result of Chen et al. (2012).

The growth rates in the three winters (i.e., 2014/15, 2015/16, 2016/17) have been calculated to investigate the interannual variability of mesoscale eddy kinetic energy (Fig. 9a). Consistent with the above analysis, the growth rate in 2016/17 was the most rapid and resulted in the most instability, which produced the strongest 10 90-day bandpassed cross-slope flow in the northern SCS (Figs. 5b,c). In winter 2014/15, the growth rate was the lowest and induced the weakest mesoscale eddy kinetic energy, which resulted in the weakest intraseasonal cross-slope flow.

The stratification ratio and vertical shear of velocity are key factors that determine the growth rate. To identify the dominant factor controlling the interannual variability, we fix either the stratification or vertical shear of velocity to the climatological value. For the winters of 2015/16 and 2016/17, the vertical shear of velocity determines the positive anomaly of growth rate (Figs. 9b,c). The stratification ratios in these winters are larger than the climatological value (Fig. 10a), but the vertical shear of velocity is enhanced, especially for 2016/17 (Fig. 10b). Further, we calculated the monthly integrated winter growth rate (i.e., $\int_{0}^{5 \times 10^{-5}} k c_{i} d k$ ) from 1950 to 2016 based on the EN4 dataset (Figs. 9d,e). When the stratification ratio is fixed to the climatological value, the integrated growth rate generally resembles the observed value with a high correlation coefficient of 0.93 (Fig. 9d); however, when the vertical shear of velocity is fixed to the climatological value, the integrated growth rate is basically uncorrelated with the observed value (Fig. 9e). Thus, the interannual variability is mainly controlled by the vertical shear of velocity.

\section{Discussion}

One possible mechanism that controls the vertical shear of velocity in the northeastern SCS is the Kuroshio 


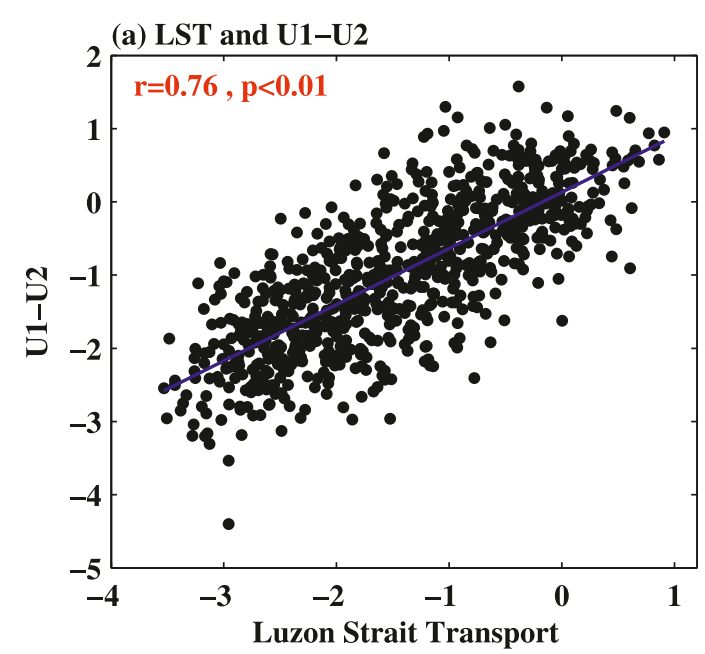

(b) Windcurl and U1-U2

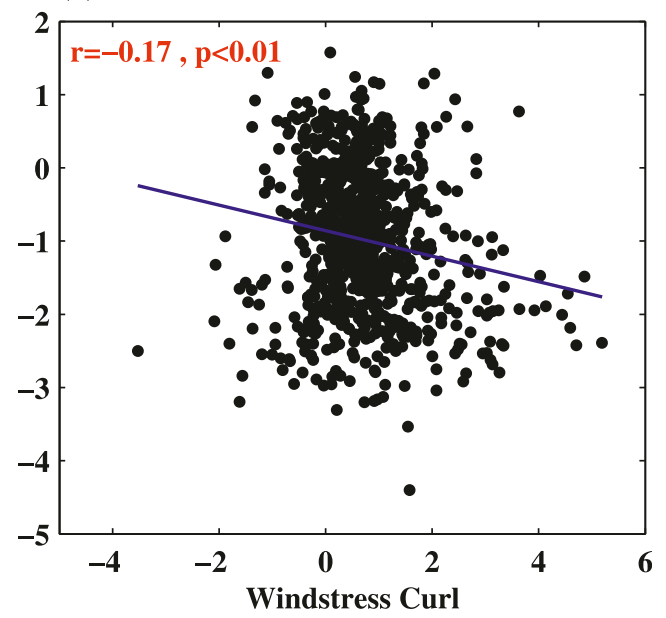

(c) Seasonal cycle: U1-U2, LST and windstress curl

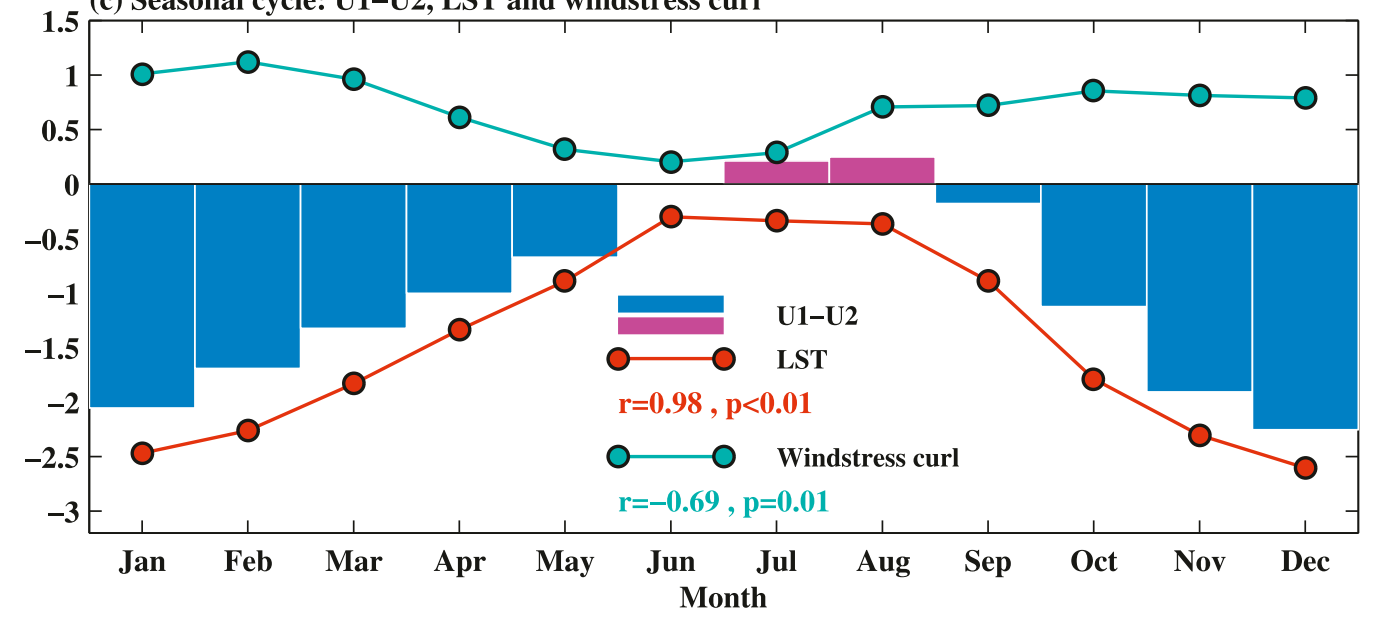

FIG. 11. Relationship between either (a) the LST or (b) the wind stress curl and the difference between upperlayer $\left(U_{1}\right)$ and lower-layer $\left(U_{2}\right)$ zonal velocities averaged within the black box marked in Fig. 6a. (c) Seasonal cycle of LST, wind stress curl, and $U_{1}-U_{2}$. All of the indices have been normalized by their respective STDs.

intrusion through the Luzon Strait. The Kuroshio intrusion inputs warm and saline water into the northeast SCS, which interacts with the SCS water, modulates the baroclinic structure in the northeast SCS and then the flow vertical structure, especially the slope flow (Gan et al. 2006; Wang et al. 2010; Wang et al. 2013b; Yang et al. 2019).

To establish the connection between the LST and the vertical shear of velocity in the northeast SCS. Based on the OFES outputs, we calculated the averaged vertical shear of zonal velocity (i.e., the upper $100-\mathrm{m}$ averaged zonal velocity minus the $100-250-\mathrm{m}$ averaged zonal velocity) within the area indicated by the black box in Fig. 6a. The vertical shear of zonal velocity in the northeast SCS is closely related to the LST with a correlation of 0.76 (Fig. 11a). When the intrusion is strong (weak), the vertical shear of velocity is enhanced (weakened) due to the baroclinic effect of Kuroshio intrusion (Wang et al. 2020b). However, the relationship between the local wind stress curl and the vertical shear of zonal velocity in the northeast SCS is loose (Fig. 11b). On the seasonal cycle, the vertical shear of zonal velocity is also related to the LST, and the wind stress curl is secondary (Fig. 11c).

\section{Conclusions}

Multiple years of mooring observations demonstrate that there is significant cross-slope flow in the northern SCS, and this flow is dominated by the intraseasonal 
variability, with the 10-90-day bandpassed cross-slope flow contributing $74.6 \%$ of the total cross-slope flow variability. In contrast, the contribution of the 10-90-day bandpassed along-slope flow to its total variability reduces to $54.4 \%$. The directions of both the 10-90-day bandpassed cross-slope and along-slope flow are almost unchanged vertically in the observed layers. However, the second EOF mode of along-slope flow is also significant.

The amplitude of the 10-90-day bandpassed crossslope flow intensifies in the boreal winter half year and presents significant difference among years. Both the seasonal and interannual variability are attributed to variations in mesoscale eddy kinetic energy.

In winter, there is a rapid baroclinic instability growth rate west to the Luzon Strait, which induces the vigorous mesoscale eddy kinetic energy. In summer, the background field only marginally satisfies the conditions for baroclinic instability, and mesoscale eddy kinetic energy weakens. This seasonal cycle of background baroclinic instability results in the winter maximum of the intraseasonal variability of cross-slope flow.

The interannual variability of baroclinic instability growth rate is mainly determined by the vertical shear of velocity. The strongest velocity vertical shear that occurred in winter of 2016/17 resulted in the most rapid baroclinic instability growth rate and the strongest 10-90-day bandpassed cross-slope flow. The vertical shear of velocity in the northern SCS is mainly determined by the Luzon Strait transport.

Acknowledgments. The satellite altimeter data are available online (https://www.aviso.altimetry.fr/en/home. html), as are the EN4, HYCOM, and WOA01 data (http://apdrc.soest.hawaii.edu/data/data.php). This work is supported by the National Natural Science Foundation of China (Grant 41676012), the Key Special Project for Introduced Talents Team of Southern Marine Science and Engineering Guangdong Laboratory (Guangzhou) (GML2019ZD0304), National Natural Science Foundation of China (Grants 41731173, 41776026,41806035, and 41676010), National Key Research and Development Program (2017YFA0603201), and National Natural Science Foundation of China (Grants 41521005, 41776025, and 41606030). Qiang Wang is also sponsored by Pearl River S\&T Nova Program of Guangzhou (201906010051) and the Independent Research Project Program of State Key Laboratory of Tropical Oceanography (LTOZZ1902). The ADCP velocity profiles are supplied by the Xisha Deep Sea Observatory, a member of the Network of Field Observation and Research Stations of the Chinese Academy of Sciences. The numerical calculation is supported by the high-performance computing division and Ms. Dandan Sui and Dr. Wei Zhou of the South China Sea Institute of Oceanology.

\section{REFERENCES}

Chen, G., and H. Xue, 2014: Westward intensification in marginal seas. Ocean Dyn., 64, 337-345, https://doi.org/10.1007/s10236014-0691-z.

_ J. J. Gan, Q. Xie, X. Chu, D. Wang, and Y. Hou, 2012: Eddy heat and salt transports in the South China Sea and their seasonal modulations. J. Geophys. Res., 117, C05021, https:// doi.org/10.1029/2011JC007724.

Chen, H., X. Xie, D. V. Rooij, T. Vandorpe, H. Li, L. Guo, and M. Su, 2013: Depositional characteristics and spatial distribution of deep-water sedimentary systems on the northwestern middle-lower slope of the northwest sub-basin, South China Sea. Mar. Geophys. Res., 34, 239-257, https://doi.org/ 10.1007/s11001-013-9191-7.

_ W. Whan, L. Li, and M. Wen, 2017: Occurrence of submarine canyons, sediment waves and mass movements along the northern continental slope of the South China Sea. J. Earth Syst. Sci., 126, 73, https://doi.org/10.1007/s12040-017-0844-9.

Cheng, L., Z. Zhang, W. Zhao, and J. Tian, 2015: Temporal variability of the current in the northeastern South China Sea revealed by 2.5-year-long moored observations. J. Oceanogr., 71, 361-372, https://doi.org/10.1007/s10872-015-0295-3.

Chow, C., J. Hu, L. Centurioni, and P. P. Niiler, 2008: Mesoscale Dongsha Cyclonic Eddy in the northern South China Sea by drifter and satellite observations. J. Geophys. Res., 113, C04018, https://doi.org/10.1029/2007JC004542.

Chu, X., G. Chen, and Y. Qi, 2020: Periodic mesoscale eddies in the South China Sea. J. Geophys. Res. Oceans, 125, e2019JC015139, https://doi.org/10.1029/2019jc015139.

Dong, C., X. Lin, Y. Liu, F. Nencioli, Y. Chao, Y. Guan, T. Dickey, and J. McWilliams, 2012: Three-dimensional eddy analysis in the Southern California Bight. J. Geophys. Res., 117, C00H14, https://doi.org/10.1029/2011JC007354.

_ J. C. McWilliams, Y. Liu, and D. Chen, 2014: Global heat and salt transports by eddy movement. Nat. Commun., 5, 3294, https://doi.org/10.1038/ncomms4294.

Fang, Y., C. Tana, S. Sun, and B. Liu, 2013: Impact of the climate change on the western boundary current in the South China Sea: An assessment based on numerical simulations. Malaysian J. Sci., 32, 347-356.

Feng, B. X., H. L. Liu, P. F. Lin, and Q. Wang, 2017: Meso-scale eddy in the South China Sea simulated by an eddy resolving ocean model. Acta Oceanol. Sin., 36, 9-25, https://doi.org/ 10.1007/s13131-017-1058-3.

Gan, J., and T. Qu, 2008: Coastal jet separation and associated flow variability in the southwest South China Sea. Deep-Sea Res. I, 55, 1-19, https://doi.org/10.1016/j.dsr.2007.09.008.

—, H. Li, E. Curchitser, and D. Haidvogel, 2006: Modeling South China Sea circulation: Response to seasonal forcing regimes. J. Geophys. Res., 111, C06034, https://doi.org/ 10.1029/2005JC003298.

_ Z Z. Q. Liu, and R. X. Huang, 2016: A three-layer alternating spinning circulation in the South China Sea. J. Phys. Oceanogr., 46, 2309-2315, https://doi.org/10.1175/JPO-D-16-0044.1.

Good, S. A., M. J. Martin, and N. A. Rayner, 2013: EN4: Quality controlled ocean temperature and salinity profiles and monthly objective analyses with uncertainty estimates. J. Geophys. Res. Oceans, 118, 6704-6716, https://doi.org/10.1002/2013JC009067. 
Grinsted, A., J. C. Moore, and S. Jevrejeva, 2004: Application of the cross wavelet transform and wavelet coherence to geophysical time series. Nonlinear Processes Geophys., 11, 561-566, https:// doi.org/10.5194/npg-11-561-2004.

Guo, Z., T. Yang, and D. Qiu, 1985: The South China Sea Warm Current and the SW-ward current on its right side in winter (in Chinese). Trop. Oceanol., 4 (1), 1-9.

Hu, J., H. Kawamura, H. Hong, and Y. Qi, 2000: A review on the currents in the South China Sea: Seasonal circulation, South China Sea Warm Current and Kuroshio intrusion. J. Oceanogr., 56, 607-624, https://doi.org/10.1023/A:1011117531252.

Jia, Y., and Q. Liu, 2004: Eddy shedding from the Kuroshio bend at Luzon Strait. J. Oceanogr., 60, 1063-1069, https://doi.org/ 10.1007/s10872-005-0014-6.

- _ - , and W. Liu, 2005: Primary studies of the mechanism of eddy shedding from the Kuroshio bend in Luzon Strait. J. Oceanogr., 61, 1017-1027, https://doi.org/10.1007/s10872006-0018-x.

Li, L., W. D. Nowlin, and J. L. Su, 1998: Anticyclonic rings from the Kuroshio in the South China Sea. Deep-Sea Res. I, 45, 1469-1482, https://doi.org/10.1016/S0967-0637(98)00026-0.

Li, W., T. M. Alves, S. Wu, M. Rebesco, F. Zhao, L. Mi, and B. Ma, 2016: A giant, submarine creep zone as a precursor of largescale slope instability offshore the Dongsha Islands (South China Sea). Earth Planet. Sci. Lett., 451, 272-284, https:// doi.org/10.1016/j.epsl.2016.07.007.

Li, Y., L. Li, M. Lin, and W. Cai, 2002: Observation of mesoscale eddy fields in the sea southwest of Taiwan by TOPEX/Poseidon altimeter data (in Chinese). Acta Oceanol. Sin., 24, 163-170.

Lian, Z., B. N. Sun, Z. X. Wei, Y. G. Wang, and X. Y. Wang, 2019: Comparison of eight detection algorithms for the quantification and characterization of mesoscale eddies in the South China Sea. J. Atmos. Oceanic Technol., 36, 1361-1380, https:// doi.org/10.1175/JTECH-D-18-0201.1.

Nan, F., H. Xue, X. Xiu, F. Chai, M. Shi, and P. Guo, 2011: Oceanic eddy formation and propagation southwest of Taiwan. J. Geophys. Res., 116, C12045, https://doi.org/ 10.1029/2011JC007386.

Nencioli, F., C. M. Dong, T. Dickey, L. Washburn, and J. C. McWilliams, 2010: A vector geometry-based eddy detection algorithm and its application to a high-resolution numerical model product and high-frequency radar surface velocities in the Southern California Bight. J. Atmos. Oceanic Technol., 27, 564-579, https://doi.org/10.1175/2009JTECHO725.1.

Qiu, B., 1999: Seasonal eddy field modulation of the North Pacific Subtropical Countercurrent: TOPEX/Poseidon observations and theory. J. Phys. Oceanogr., 29, 2471-2486, https://doi.org/ 10.1175/1520-0485(1999)029<2471:SEFMOT >2.0.CO;2.

Qiu, C. H., H. B. Mao, J. C. Yu, Q. Xie, J. X. Wu, S. M. Lian, and Q. Y. Liu, 2015: Sea surface cooling in the northern South China Sea observed using Chinese sea-wing underwater glider measurements. Deep-Sea Res. I, 105, 111-118, https://doi.org/ 10.1016/j.dsr.2015.08.009.

_ H. Dan, C. J. Liu, Y. S. Cui, D. Y. Su, J. X. Wu, and J. Ouyang, 2019a: Upper vertical structures and mixed layer depth in the shelf of the northern South China Sea. Cont. Shelf Res., 174, 26-34, https://doi.org/10.1016/j.csr.2019.01.004.

— , H. B. Mao, H. Liu, Q. Xie, J. C. Yu, D. Su, J. Ouyang, and S. Lian, 2019b: Deformation of a warm eddy in the northern South China Sea. J. Geophys. Res. Oceans, 124, 5551-5564, https://doi.org/10.1029/2019JC015288.

Sasaki, H., M. Nonaka, Y. Masumoto, Y. Sasai, H. Uehara, and H. Sakuma, 2007: An eddy-resolving hindcast simulation of the quasi-global ocean from 1950 to 2003 on the Earth Simulator. High Resolution Numerical Modeling of the Atmosphere and Ocean, W. Ohfuchi and K. Hamilton, Eds., Springer, 157-185.

Shu, Y. Q., Q. Wang, and T. T. Zu, 2018: Progress on shelf and slope circulation in the northern South China Sea. Sci. China Earth Sci., 61, 560-571, https://doi.org/10.1007/s11430-0179152-y.

Sun, S., Y. Fang, B. Liu, and Tana, 2016: Coupling between SST and wind speed over mesoscale eddies in the South China Sea. Ocean Dyn., 66, 1467-1474, https://doi.org/10.1007/s10236016-0993-4.

- — - Y. Zu, B. Liu, Tana, and A. A. Samah, 2020: Seasonal characteristics of mesoscale coupling between the sea surface temperature and wind speed in the South China Sea. J. Climate, 33, 625-638, https://doi.org/10.1175/JCLI-D-19-0392.1.

Sun, W., C. Dong, R. Wang, Y. Liu, and K. Yu, 2017: Vertical structure anomalies of oceanic eddies in the Kuroshio Extension region. J. Geophys. Res., 122, 1476-1496, https:// doi.org/10.1002/2016JC012226.

, - - W. Tan, Y. Liu, Y. He, and J. Wang, 2018: Vertical structure anomalies of oceanic eddies and eddy-induced transports in the South China Sea. Remote Sens., 10, 795, https://doi.org/10.3390/RS10050795.

,,-- , and Y. He, 2019: Statistical characteristics of cyclonic warm-core eddies and anticyclonic cold-core eddies in the North Pacific based on remote sensing data. Remote Sens., 11, 208, https://doi.org/10.3390/RS11020208.

Tian, J., Q. Yang, X. Liang, L. Xie, D. Hu, F. Wang, and T. Qu, 2006: Observation of Luzon Strait transport. Geophys. Res. Lett., 33, L19607, https://doi.org/10.1029/2006GL026272.

Wang, D., B. Hong, J. Gan, and H. Xu, 2010: Numerical investigation on propulsion of the counter-wind current in the northern South China Sea in winter. Deep-Sea Res. I, 57, 1206-1221, https:// doi.org/10.1016/j.dsr.2010.06.007.

, and Coauthors, 2013a: Progress of regional oceanography study associated with western boundary current in the South China Sea. Chin. Sci. Bull., 58, 1205-1215, https://doi.org/ 10.1007/s11434-012-5663-4.

—, Q. Wang, W. Zhou, S. Cai, L. Li, and B. Hong, 2013b: An analysis of the current deflection around Dongsha Islands in the northern South China Sea. J. Geophys. Res. Oceans, 118, 490-501, https://doi.org/10.1029/2012JC008429.

Wang, G., J. Su, and P. C. Chu, 2003: Mesoscale eddies in the South China Sea observed with altimeter data. Geophys. Res. Lett., 30, 2121, https://doi.org/10.1029/2003GL018532.

- D. Chen, and J. Su, 2006: Generation and life cycle of the dipole in the South China Sea summer circulation. J. Geophys. Res., 111, C06002, https://doi.org/10.1029/2005JC003314.

and - 2008: Winter eddy genesis in the eastern South China Sea due to orographic wind jets. J. Phys. Oceanogr., 38, 726-732, https://doi.org/10.1175/2007JPO3868.1.

_ C. Wang, and R. X. Huang, 2010: Interdecadal variability of eastward current in the South China Sea associated with the summer Asian monsoon. J. Climate, 23, 6115-6123, https:// doi.org/10.1175/2010JCLI3607.1.

Wang, Q., Y. X. Wang, B. Hong, W. D. Zhou, and D. X. Wang, 2011: Different roles of Ekman pumping in the west and east segments of the South China Sea Warm Current. Acta Oceanol. Sin., 30 (3), 1-13, https://doi.org/10.1007/s13131-011-0113-8.

- L. Zeng, W. Zhou, Q. Xie, S. Cai, J. Yao, and D. Wang, 2015a: Mesoscale eddies cases study at Xisha waters in the South China Sea in 2009/2010. J. Geophys. Res. Oceans, 120, 517-532, https://doi.org/10.1002/2014JC009814. 
, Y. X. Wang, W. D. Zhou, D. X. Wang, D. D. Sui, and J. Chen, 2015b: Dynamic of the upper cross isobaths flow on the north South China Sea in summer. Aquat Ecosyst Health, 18, 357-366, https://doi.org/10.1080/14634988.2015.1112124.

—, L. Zeng, J. Li, J. Chen, Y. K. He, J. L. Yao, D. X. Wang, and W. D. Zhou, 2018: Observed cross-shelf flow induced by mesoscale eddies in the northern South China Sea. J. Phys. Oceanogr., 48, 1609-1628, https://doi.org/10.1175/JPO-D-17-0180.1.

_ , and Coauthors, 2019: Energetic topographic Rossby waves in the northern South China Sea. J. Phys. Oceanogr., 49, 26972714, https://doi.org/10.1175/JPO-D-18-0247.1.

—_ and Coauthors, 2020a: Interannual variability of South China sea winter circulation: Response to Luzon Strait transport and El Niño wind. Climate Dyn., 54, 1145-1159, https://doi.org/ 10.1007/s00382-019-05050-2.

— W. D. Zhou, L. Zeng, J. Chen, Y. K. He, and D. X. Wang, 2020b: The linkage of Kuroshio intrusion and mesoscale eddy variability in the northern South China Sea: Subsurface speed maximum. Geophys. Res. Lett., 47, e2020GL087034, https:// doi.org/10.1029/2020gl087034.

Wang, X., and Coauthors, 2018: Controls of contour currents on intra-canyon mixed sedimentary processes: Insights from the Pearl River Canyon, northern South China Sea. Mar. Geol., 406, 193-213, https://doi.org/10.1016/j.margeo.2018.09.016.

Wyrtki, K., 1961: Physical oceanography of the Southeast Asian waters. Scripps Institution of Oceanography Naga Rep. 2, 195 pp.

Xia, C. S., K. T. Jung, G. S. Wang, X. Q. Yin, and J. S. Guo, 2016: Case study on the three-dimensional structure of meso-scale eddy in the South China Sea based on a high-resolution model. Acta Oceanol. Sin., 35, 29-38, https://doi.org/10.1007/s13131016-0805-1.

Xie, S. P., Q. Xie, D. Wang, and W. T. Liu, 2003: Summer upwelling in the South China Sea and its role in regional climate variations. J. Geophys. Res., 108, 3261, https://doi.org/10.1029/2003JC001867.

Xiu, P., F. Chai, L. Shi, H. J. Xue, and Y. Chao, 2010: A census of eddy activities in the South China Sea during 1993-2007. J. Geophys. Res., 115, C03012, https://doi.org/10.1029/2009JC005657.

Yang, H., and Q. Liu, 2003: Forced Rossby wave in the northern South China Sea. Deep-Sea Res. I, 50, 917-926, https://doi.org/ 10.1016/S0967-0637(03)00074-8.

Yang, Y., and Coauthors, 2019: Eddy-induced transport of saline Kuroshio water into the northern South China Sea. J. Geophys. Res. Oceans, 124, 6673-6687, https://doi.org/ 10.1029/2018JC014847.

Yuan, D., 2002: A numerical study of the South China Sea deep circulation and its relation to the Luzon Strait transport. Acta Oceanol. Sin., 21, 187-202.

, W. Han, and D. Hu, 2006: Surface Kuroshio path in the Luzon Strait area derived from satellite remote sensing data. J. Geophys. Res., 111, C11007, https://doi.org/10.1029/2005JC003412.
- — - , and -2007 : Anti-cyclonic eddies northwest of Luzon in summer-fall observed by satellite altimeters. Geophys. Res. Lett., 34, L13610, https://doi.org/10.1029/ 2007 GL029401.

Zeng, L., D. Wang, P. Xiu, Y. Shu, Q. Wang, and J. Chen, 2016: Decadal variation and trends in subsurface salinity from 1960 to 2012 in the northern South China Sea. Geophys. Res. Lett., 43, 12 181-12 189, https://doi.org/10.1002/2016GL071439.

Zhang, Z., W. Zhao, J. Tian, Q. Yang, and T. Qu, 2015: Spatial structure and temporal variability of the zonal flow in the Luzon Strait. J. Geophys. Res. Oceans, 120, 759-776, https:// doi.org/10.1002/2014JC010308.

,$- \ldots$, B. Qiu, and J. Tian, 2017: Anticyclonic eddy sheddings from Kuroshio loop and the accompanying cyclonic eddy in the northeastern South China Sea. J. Phys. Oceanogr., 47, 1243-1259, https://doi.org/10.1175/JPO-D-16-0185.1.

_ J. W. Tian, B. Qiu, W. Zhao, P. Chang, D. X. Wu, and X. Q. Wan, 2016: Observed 3D structure, generation, and dissipation of oceanic mesoscale eddies in the South China Sea. Sci. Rep., 6, 24 349, https://doi.org/10.1038/srep24349.

Zhao, R. X., and X. H. Zhu, 2016: Weakest winter South China Sea western boundary current caused by the 2015-2016 El Niño event. J. Geophys. Res. Oceans, 121, 7673-7682, https:/ doi.org/10.1002/2016JC012252.

—_ - and X. Y. Guo, 2017: The impact of monsoon winds and mesoscale eddies on thermohaline structures and circulation patterns in the northern South China Sea. Cont. Shelf Res., 143, 240-256, https://doi.org/10.1016/j.csr.2016.06.009.

Zhu, X. H., R. X. Zhao, X. Guo, Y. Long, Y. Ma, and X. Fan, 2015: A long-term volume transport time series estimated by combining in situ observation and satellite altimeter data in the northern South China Sea. J. Oceanogr., 71, 663-673, https:// doi.org/10.1007/s10872-015-0305-5.

Zhuang, W., S.-P. Xie, D. Wang, B. Taguchi, H. Aiki, and H. Sasaki, 2010a: Intraseasonal variability in sea surface height over the South China Sea. J. Geophys. Res., 115, C04010, https://doi.org/10.1029/2009JC005647.

— , Y. Du, D. X. Wang, Q. Xie, and S. P. Xie, 2010b: Pathways of mesoscale variability in the South China Sea. Chin. J. Oceanology Limnol., 28, 1055-1067, https://doi.org/10.1007/ s00343-010-0035-x.

Zu, T., D. X. Wang, C. X. Yan, I. Belkin, W. Zhuang, and J. Chen, 2013: Evolution of an anticyclonic eddy southwest of Taiwan. Ocean Dyn., 63, 519-531, https://doi.org/10.1007/ s10236-013-0612-6.

Zu, Y. C., S. W. Sun, W. Zhao, P. L. Li, B. C. Liu, Y. Fang, and A. A. Samah, 2019: Seasonal characteristics and formation mechanism of the thermohaline structure of mesoscale eddy in the South China Sea. Acta Oceanol. Sin., 38, 29-38, https:// doi.org/10.1007/s13131-018-1222-4. 